\title{
Textural Changes of Asparagus in Relation to Delays in Cooling and Storage Conditions
}

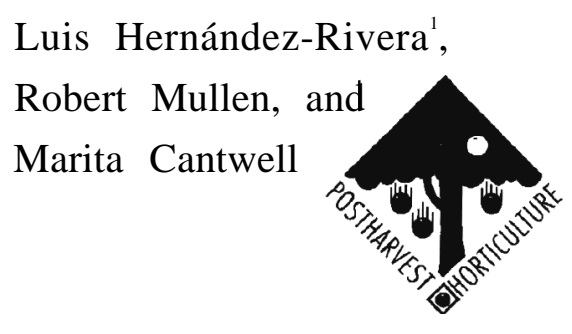

Additional index words. Asparagus officinalis, shear force

Summary. Asparagus (Asparagus officinalis L.) spears (cv. UC 157) trimmed to $20 \mathrm{~cm}$ were cooled $0,4,8$, 12, 16, and 20 hours after harvest and evaluated for resistance to shear at 5 and $10 \mathrm{~cm}$ above the cut end immediately after cooling and during storage at $0.5,2.5$, and $5 \mathrm{C}$. Resistance to shear increased during cooling delays and with time in storage. Initial cooling delays and simulated marketing conditions (transfer to $15 \mathrm{C}$ for 1 day) were the principal causes of increased resistance to shear. A 4-hour cooling delay resulted in an average $40 \%$ increase in resistance to shear. Transfer to $15 \mathrm{C}$ for 1 day resulted in a greater increase in shear force in the rapidly cooled than in the delayed-cooled spears. Increases in resistance to shear during storage varied from $0 \%$ to $50 \%$ and depended on the storage temperature, time, and the initial cooling delay. Spears trimmed to a green base showed less increase in shear force after storage than did spears trimmed to a white base. The visual quality of asparagus stored for 14 days was similar (excellent) among spears from different storage temperatures and between greenand white-base spears. Storage quality after 24 days had decreased more in spears stored at $5 \mathrm{C}$ than at 2.5 or $0.5 \mathrm{C}$, and more in the green-base than the white-base spears. 
$\mathrm{T}$ exture is one of the most important quality attributes of asparagus spears. Increased toughness of spears is principally due to increases in fiber content and fiber lignification, both of which may be modified by preharvest growing conditions and postharvest handling (Lipton, 1990). Many instruments and methods have been used to assess textural changes in asparagus spears. Resistance to shear force is highly correlated to sensory, chemical, and histochemical determinations of fiber and lignin and is a widely used technique (Clore et al., 1976; Lipton, 1990; Saltveit, 1988; Sharma et al., 1975a; Wagenvoort and Ammerlaan, 1988). Shear force measurements are a combination of shearing, crushing, and compression forces. Variations in the blade width, positioning of the blade along the spear, spear diameter, number of spears sheared per measurement, and other factors lead to considerable variation in absolute shear force values. Adequately snapped spears were reported to have shear force measurements of $\approx 30 \mathrm{~kg}$ (Werner et al., 1963), and this value was used to estimate usable portions of spears (Saltveit, 1988).

The importance of reducing temperature to maintain asparagus quality is well documented (Lipton, 1990). Many compositional and physiological changes occur during the period immediately following harvest, especially in the actively growing tip portion of the spear. The most rapid texture changes after harvest occur, however, in the basal portion of the spear. Sharma et al. (1975b) described an equation to predict asparagus texture changes with time and temperature. This equation was derived from data they had collected from spears of various lengths and diameters stored at 0 to $32 \mathrm{C}$ for up to $72 \mathrm{~h}$. Lipton (1990) reported that the equation greatly underestimated shear forces when the data of Clore et al. (1976), based on a 7-day storage period, were used.

Notwithstanding the importance of temperature to harvested asparagus quality, handling details, such as the time from harvest to cooling, usually are not reported in postharvest storage studies (Lipton, 1990). In commercial production of asparagus there may be many hours' delay between harvest and cooling, especially during peak production periods that necessarily occur in conjunction with high temperatures.
Occasionally field bins are stored overnight in a cold room before packing, and the slow removal of field heat undoubtedly diminishes asparagus quality.

The objectives of this study were to: 1) determine the impact of delays in cooling on the texture of asparagus spears before and during storage; and 2) compare the postharvest quality and texture of white- and green-base spears. Such information, based on normal cooling delays and storage conditions, provides additional criteria for making appropriate postharvest handling decisions .

\section{Materials and Methods}

Asparagus spears of cultivar UC $157\left(\mathrm{~F}_{1}\right), 1.5$ to $1.9 \mathrm{~cm}$ in diameter and 20 to $23 \mathrm{~cm}$ long, were harvested from two commercial fields near Tracy and Stockton, Calif., and placed loosely into $15-\mathrm{kg}$ plastic field containers with polyethylene liners. Containers were transported $(2 \mathrm{~h})$ to the Mann Laboratory in a covered vehicle at ambient temperature $(\approx 25 \mathrm{C}$ ) and subsequently kept at $25 \mathrm{C}$ until cooled. Under these conditions spears lost $0.2 \%$ fresh weight/h. Spears were cooled by submerging them for 15 min in a coldwater bath $(2.5 \mathrm{C})$ in the field $(0-\mathrm{h}$ delay) or the laboratory to achieve delays in cooling of $0,4,8,12,16$, and $20 \mathrm{~h}$. Spears absorbed $1.2 \%$ of their fresh weight in water during hydrocooling. Spears were trimmed to $20 \mathrm{~cm}$ (white-base), unless otherwise specified, and washed with water containing $50 \mathrm{ppm}$ chlorine. Spears then were placed vertically in glass containers at the indicated temperatures on paper towels moistened with distilled water in an air-flow system (spears lost
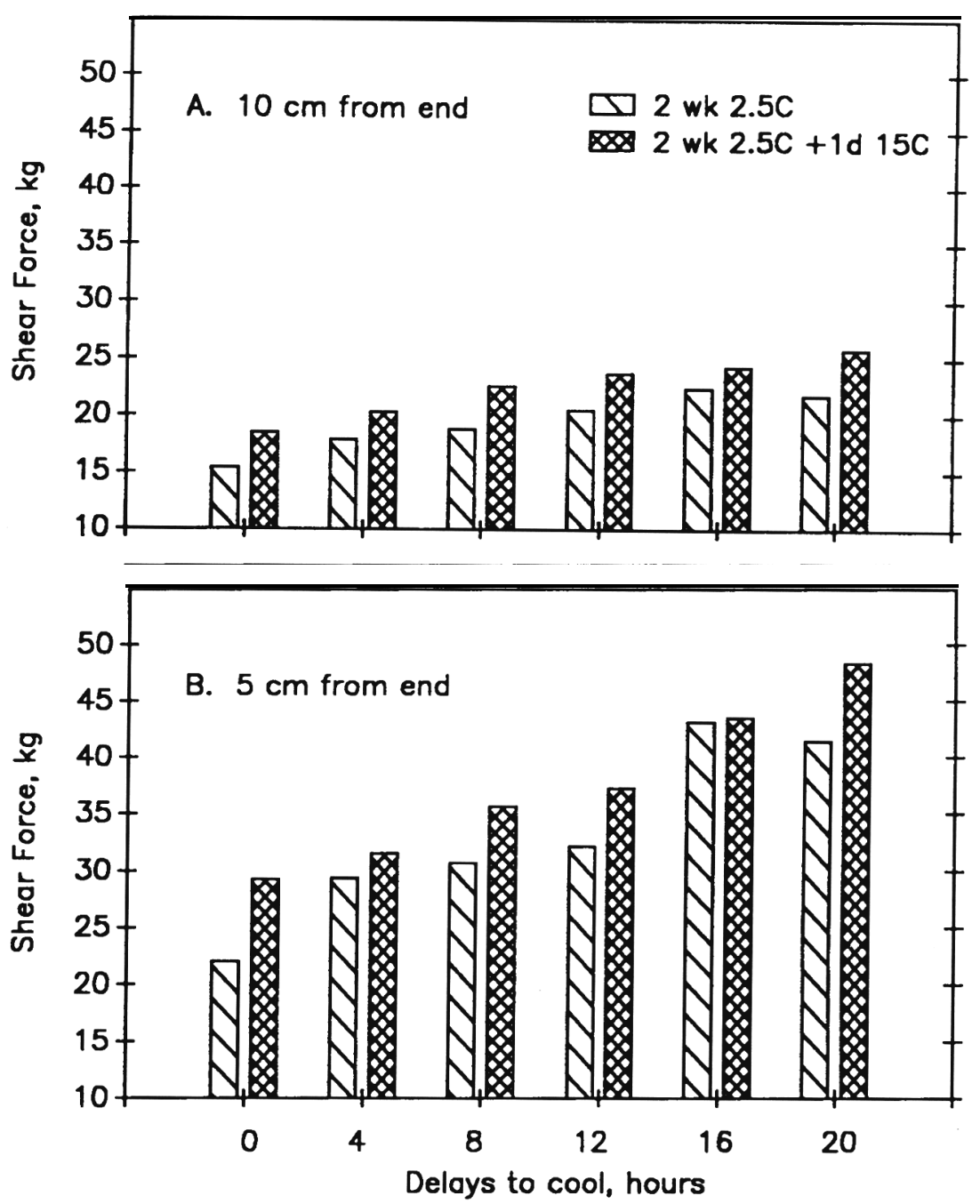

Fig. 1. Changes in the force required to shear asparagus spears after cooling delays and subsequent storage at 2.5C for 2 weeks, followed by transfer to $15 \mathrm{C}$ for 1 day. Shear force values were measured on 12 spears per treatment $5 \mathrm{~cm}(A)$ and $10 \mathrm{~cm}(B)$ from the cut ends. Mean separation by $L S D=5.0$. 
Table 1. Changes in the force required to shear asparagus spears after cooling delays and subsequent transfer to 15C. Spears were kept at $25 \mathrm{C}$ and then hydrocooled for $15 \mathrm{~min}$ in $2.5 \mathrm{C}$ water. Shear force values were measured $5 \mathrm{~cm}$ from the cut end of fifteen 20-cm-long-spears per evaluation

\begin{tabular}{lcc}
\hline & \multicolumn{2}{c}{ Shear force $(\mathbf{k g})$} \\
\cline { 2 - 3 } Delay to cool $(\mathbf{h})$ & After cooling & $\begin{array}{c}\text { After cooling }+ \\
\text { transfer to } 15 \mathrm{C} \text { for } \mathbf{1} \text { day }\end{array}$ \\
\hline \hline 0 & 22.5 & 33.0 \\
4 & 29.8 & 39.0 \\
8 & 32.4 & 37.4 \\
12 & 35.6 & 42.1 \\
16 & 40.8 & 45.0 \\
20 & 44.0 & 45.5 \\
LSD $0.05=7.0$ & & \\
\hline
\end{tabular}

$<1 \%$ fresh weight during storage). Humidified air was passed through the containers at a rate sufficient to maintain $\mathrm{CO}_{2}$ levels $<0.5 \%$. Asparagus was stored at $0.5 \mathrm{C} \pm 0.25 \mathrm{C}, 2.5 \mathrm{C} \pm 0.25 \mathrm{C}$, or $5 \mathrm{C} \pm 0.5 \mathrm{C}$.

Spears were evaluated for visual quality by a hedonic rating scale where $9=$ excellent, $7=$ good, $5=$ fair, $3=$ poor, and 1 = unusable. Texture measurements were determined by an Allo-Kramer Shear Press equippedwith a single 3-mm-wide blade at a loading rate of $2.5 \mathrm{cmžmin}^{-1}$. The shear force was measured as the maximum peak force required to cut through individual spears 5 or $10 \mathrm{~cm}$ from their cut ends. Data are the averages of 12 or 15 spears per treatment per evaluation period. Results were analyzed by threeor four-factor analysis ofvariance, with mean separations by LSD at $P=0.05$.

\section{Results and Discussion}

Delays in cooling asparagus spears from 25 to $2.5 \mathrm{C}$ greatly increased resistance to shear values (Table 1). A $31 \%$ increase in shear force occurred within $4 \mathrm{~h}$ at $25 \mathrm{C}$, and shear force values continued to increase as the time to cooling increased. After a 20$\mathrm{h}$ delay in cooling, shear force values had doubled. When spears were subjected to simulated marketing conditions (1 day at 15C), the increases in shear force were greatest for those spears that had been cooled immediately. These spears showed a $47 \%$ increase in shear force value after transfer, whereas spears that had been cooled at some time after $8 \mathrm{~h}$ ofharvest showed only an $8 \%$ to $15 \%$ increase. Final shear force values, however, were greater for those spears in which there had been a cooling delay.

A similar trend was observed in spears subjected to delayed cooling and stored at 2.5C for 2 weeks (Fig. 1). Measurements at $5 \mathrm{~cm}$ from the cut end (Fig. la) showed that a cooling delay of $4 \mathrm{~h}$ resulted in a $34 \%$ increase in shear force, which was of the same order as that observed previously (Table $1)$. The greatest change after transfer was associated with spears that had been cooled immediately ( $32 \%$ increase upon transfer). This increase in shear force was less than the corresponding increase measured in the freshly harvested nonstored spears (Table 1). This is consistent with previous observations that the rate of increase of textural changes decreases with time in storage (Lipton, 1957).

Cooling 4 to $20 \mathrm{~h}$ after harvest resulted in continuously increasing shear force values $5 \mathrm{~cm}$ from the cut ends after storage and transfer, but the increase after transfer was limited to $\leq 16 \%$ (Fig. 1A). Shear force values 10 $\mathrm{cm}$ from the cut end were much lower but showed a similar trend as cooling delays and transfer to 15C (Fig. 1B).

Table 2 summarizes the forces required to shear spears stored at 2.5 or 5C after initial cooling delays. During the first 2 weeks ofstorage there were no significant differences in shear force values between spears stored at 2.5 and $5 \mathrm{C}$ for a given cooling period. This was also true for spears that had been cooled within $8 \mathrm{~h}$ of harvest and stored for 24 days. The most important factor determining resistance to shear was the initial delay in cooling the asparagus to an appropriate storage temperature. Storage in the range of 2.5 to $5 \mathrm{C}$ stopped most increases in shear force resistance for 14 days. By 24 days ofstorage, shear force values of spears cooled at any time after harvest were consistently higher at 5 than at $2.5 \mathrm{C}$. Visual quality of spears stored for 14 days at 2.5 and $5 \mathrm{C}$ remained excellent. After 24 days ofstorage, visual quality declined to a score of 5 (fair).

Modified atmospheres, principally involving increases in $\mathrm{CO}_{2}$ concentration, are known to affect asparagus spear texture (Lipton, 1990). Exposure of spears to $>6 \% \mathrm{CO}_{2}$ resulted in tenderization or reduced shear force values after 1 week at 2C (Lougheed and Dewey, 1966). Such treatments, which are applied commercially to some palletized air shipments, effectively reduce the consequences of poor temperature management. Most aspara-

Table 2. Changes in the force required to shear asparagus spears after initial cooling delays and subsequent storage at 2.5 or 5 C for 24 day 3 . Shear force values are averages from twelve 20-cm-long spears measured $5 \mathrm{~cm}$ from the cut end.

\begin{tabular}{|c|c|c|c|c|c|c|c|c|}
\hline \multirow[b]{2}{*}{ Delay to cool (h) } & \multicolumn{4}{|c|}{ Days of storage at $2.5 \mathrm{C}(\mathrm{no})}$. & \multicolumn{4}{|c|}{ Days of storage at $5 C$ (no.) } \\
\hline & $\mathbf{0}$ & 7 & 14 & 24 & $\mathbf{0}$ & 7 & 14 & 24 \\
\hline & \multicolumn{8}{|c|}{ Shear force $(\mathrm{kg})$} \\
\hline 0 & 20.5 & 22.6 & 22.1 & 29.9 & 22.6 & 23.7 & 24.5 & 36.0 \\
\hline 4 & 29.8 & 29.6 & 31.6 & 38.2 & 28.8 & 32.0 & 30.3 & 43.1 \\
\hline 8 & 32.4 & 27.0 & 31.8 & 38.8 & 35.7 & 31.2 & 33.6 & 43.2 \\
\hline 12 & 35.6 & 34.7 & 35.9 & 41.9 & 36.0 & 33.5 & 39.6 & 50.2 \\
\hline 16 & 40.8 & 38.8 & 44.4 & 42.2 & 43.0 & 38.4 & 45.2 & 51.3 \\
\hline $\begin{array}{l}20 \\
L S D 0.05=6.5\end{array}$ & 43.3 & 43.2 & 44.0 & 44.6 & 45.7 & 42.7 & 46.2 & 52.1 \\
\hline
\end{tabular}

${ }^{8}$ Spears were kept at $25 \mathrm{C}$ before cooling for 15 min in $2.5 \mathrm{C}$ or $5 \mathrm{C}$ water. 
Table 3. Changes in the force required to shear asparagus spears stored at 0.5 or $5 \mathrm{C}$. Spears were cooled $4 \mathrm{~h}$ after harvest and trimmed to a 20 -cm length (white base) or a 19-cm length (green base). Shear force measurements were made at 5 and $10 \mathrm{~cm}$ from the cut end of the initial 20-cm length and are the averages of 12 spears.

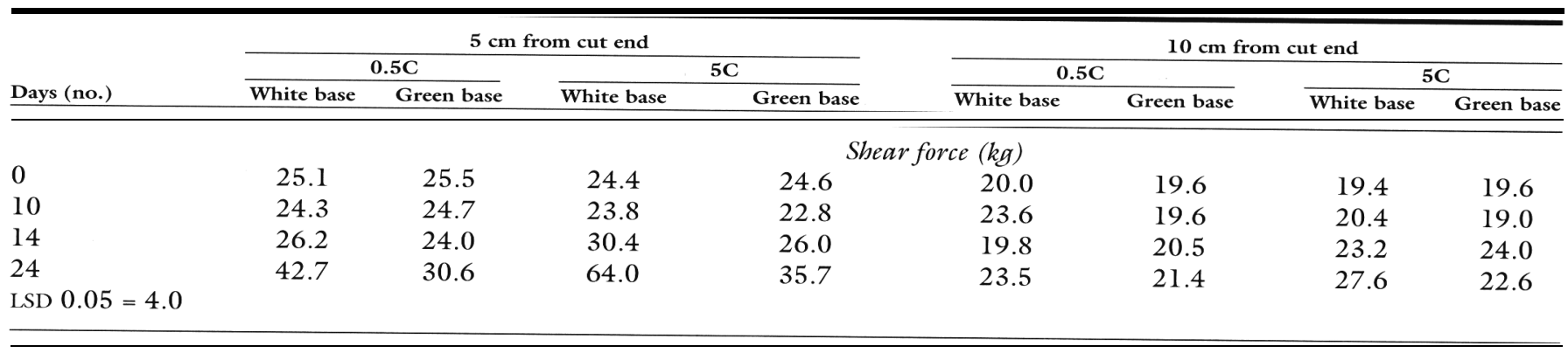

Table 4. Changes in the visual quality scores of asparagus spears after storage at $0.5 \mathrm{C}$ or $5 \mathrm{C}$. Spears were cooled $4 \mathrm{~h}$ after harvest and trimmed to a 20 cm length (white base) or a 19-cm length (green base). Visual quality, of the base and tip portions of the spear was determined by a hedonic rating scale.

\begin{tabular}{|c|c|c|c|c|c|c|c|c|}
\hline \multirow[b]{3}{*}{ Days (no.) } & \multicolumn{4}{|c|}{ Base of spear } & \multicolumn{4}{|c|}{ Tip of spear } \\
\hline & \multicolumn{2}{|c|}{$\begin{array}{c}0.5 \mathrm{C} \\
\end{array}$} & \multicolumn{2}{|c|}{$5 \mathrm{C}$} & \multicolumn{2}{|c|}{$0.5 \mathrm{C}$} & \multicolumn{2}{|c|}{$5 \mathrm{C}$} \\
\hline & White base & Green base & White base & Green base & White base & Green base & White base & Green base \\
\hline & \multicolumn{8}{|c|}{ Visual quality score } \\
\hline 0 & 9.0 & 9.0 & 9.0 & 9.0 & 9.0 & 9.0 & 9.0 & 9.0 \\
\hline 10 & 9.0 & 9.0 & 8.8 & 8.8 & 8.7 & 8.7 & 8.6 & 7.7 \\
\hline 14 & 9.0 & 9.0 & 9.0 & 8.7 & 8.8 & 8.8 & 8.7 & 8.1 \\
\hline $\begin{array}{l}24 \\
\operatorname{LSD} 0.05=0.8\end{array}$ & 8.8 & 8.7 & 5.2 & 2.4 & 8.2 & 8.2 & 5.3 & 3.6 \\
\hline
\end{tabular}

${ }^{7}$ Hedonic rating scale where $9=$ excellent and $1=$ unusable.

gus, however, is shipped without modified atmosphere treatment. Effective temperature management, including prompt cooling and expedited handling, is required to control spear toughening as well as spear deterioration.

Asparagus spears are often trimmed to a base of white or green tissue; the latter is considered asparagus of higher commercial quality because it contains less fiber and lignified tissue. The differences in texture between the whiteand green-base spears were few until the latter part of the storage period (Table 3 ). Trimming affected the shear force values measured $5 \mathrm{~cm}$ from the end of the original-length spears after 24 days of storage, with higher force values registered in the white- base spears at 5C. There were no significant shear force differences between green- and white-base spears stored at $0.5 \mathrm{C}$ when measured $10 \mathrm{~cm}$ from the cut end; there were, however, significant differences after 24 days at 5C. Increased lignification and toughening of the asparagus spear are associated with high phenylalanine ammonia lyase activity (Lipton, 1990). Textural differences of whiteand green-base spears are consistent with reported variations in activity of this enzyme in different portions of the spear (Lipton, 1990).
Visual quality declined more in the green-base than the white-base spears when stored at 5C (Table 4), and this decrease was associated closely with visual symptoms of bacteria-induced decay. There were no significant differences in visual quality between the two types of spears when stored at $0.5 \mathrm{C}$ for up to 24 days. There were no symptoms of chilling injury in spears stored at $0.5 \mathrm{C}$ for 24 days.

The results reported here re-emphasize the fact that textural changes in asparagus are extremely responsive to temperature and delays in cooling. Cooling should be achieved within 4 $\mathrm{h}$, since even this delay, which may occur commonly in commercial handling, resulted in large increases in shear force values. Much less change occurred over long periods of lowtemperature storage than occurred within the first hours of harvest. To maintain visual and textural quality, asparagus needs closely coordinated and expedited handling after harvest.

\section{Literature Cited}

Clore, W.J., G.H. Carter, and S.R. Drake. 1976. Pre- and postharvest factors affecting textural quality of fresh asparagus. J. Amer. Soc. Hort. Sci. 101(5):576-578.
Lipton, W.J 1990. Postharvest biology of fresh asparagus. Hort. Rev. 12:69-155.

Lougheed, E.C. and D.H. Dewey. 1966. Factors affecting the tenderizing effect of modified atmospheres on asparagus spears during storage. Proc. Amer. Soc. Hort. Sci. 89:336-345.

Saltveit, M.E., Jr. 1988. Postharvest glyphosate application reduces toughening, fiber content, and lignification of stored asparagus spears. J. Amer. Soc. Hort. Sci. 113(4):569-572.

Sharma, S. C., R. R. Wolfe, and N.F. Haard. $1975 a$. Evaluation of methods for measuring asparagus texture. J. Food Sci. 40:10211024.

Sharma, S.C., R.R. Wolfe, and S.S. Wang $1975 \mathrm{~b}$. Kinetic analysis ofpost-harvest texture changes in asparagus. J. Food Sci. 40:1147-1151.

Wagenvoort, W.A. and A.W.S. Ammerlaan. 1988. Methods for analysing the fibrousness of forced asparagus spears in hydroculture and in the field. Gartenbauwissenschaft 53:38-41.

Werner, G., E.E. Meschter, H. Lacey, and A. Kramer. 1963. Use of the press in determining fibrousness of raw and canned green asparagus. Food Technol. 15:81-86. 